\title{
Value diagnostic of FNA in Glan Clwyd Head and Neck Unit
}

\section{Garlea-Robu, E Prades, O Tkachuk, Z Hammad, A Arya, V Puranik, H Zeitoun, Mohan A ENT Department Glan Clwyd Hospital, Wales, United Kingdom}

\section{- Background:}

There was a need to know our management of FNA in nonThyroid Head and Neck cancer and comparing our results to a current good reference was an opportunity to see if there was a room for improvement.

\section{- Methods:}

We reviewed one year of FNA performed by Pathology department and related to Non-thyroidal Head and Neck lesions. Main results were Diagnostic Value of FNA by means of Sensitivity, Specificity, Accuracy, Positive Predictive Value and Negative Predictive Value.

- Results:

Our pathology department manage to get similar percentages of Benign and Malignant pathology when comparing to a reference (Goret et al 2013). 20.6 percent of patients required FNA due to inadequacy of the sample.

\begin{tabular}{l|l|l|} 
& Reference (n=866) & Our Study (n=383) \\
\hline Inadequate (C1) & $17,3 \%$ & $20,6 \%$ \\
\hline Benign (C2) & $56,4 \%$ & $36,6 \%$ \\
\hline Most likely Benign (C3) & $0,01 \%$ & $10,7 \%$ \\
\hline Most likely Malignant (C4) & $8,1 \%$ & $6,9 \%$ \\
\hline Malignant (C5) & $21,4 \%$ & $25,2 \%$ \\
\hline Total cases & $\mathrm{N}=248$ & $\mathrm{~N}=131$
\end{tabular}

Main results showed that there is an acceptable diagnostic value for FNA when comparing to concurrent published data.
- Positive Predictive Value and Specificity were almost perfect (98\%). Accuracy was still outstanding (90\%). However, results from Sensitivity (81\%) and Negative Predictive Value (84\%) were acceptable but in the low end of acceptability. This was due to 9 False negative and one false positive over a 131 patients for what we had histology.

\begin{tabular}{|l|l|l|l}
\hline Type & Local & FNA & Histology \\
\hline F- & LN & Granulomatous Lymphadenitis $4 \mathrm{~cm}$ & Left SCC Tonsil \\
\hline F- & LN & Granulomatous Lymphadenitis & Lymphoma B cell \\
\hline F- & LN & Branchial cyst vs well diff SCC & SCC \\
\hline F- & LN & Reactive Lymph node & Hodgkin L \\
\hline F- & LN & Reactive Lymph node & Hodgkin L \\
\hline F- & LN & Normal Tissue neck area II & SCC Tonsil \\
\hline F- & Neck & Thyroglossal cyst & Papillary Carcinoma \\
\hline F- & Neck & Haemorragic cyst & Mx SCC \\
\hline F- & Parotid & Pleomorphic Adenoma & SCC \\
\hline F+ & LN & Non Hodgkin L & Florid Reactive Hyperplasia \\
\hline
\end{tabular}

\section{- Discussion:}

Patients who needed a second FNA on the basis of inadequacy of the first one may experiment different levels of delay regarding clinical and logistic considerations.

Possibility to develop a ONE STOP HEAD AND NECK CANCER CLINIC in the future as in other Hospitals could reduce need for second FNA.

\begin{tabular}{|c|c|c|c|c|c|c|c|}
\hline Diagnosis & Year & N & Se & Sp & Accuracy & PPV & NPV \\
\hline Our & 2016 & 383 & 81 & 98 & 90 & 98 & 84 \\
\hline Goret * & 2013 & 866 & 98 & 97 & 96 & 96 & 97 \\
\hline Addams & 2009 & 238 & 92 & 90 & - & 92 & 90 \\
\hline Ersoz & 1998 & 584 & 78 & 94 & 89 & 89 & 88 \\
\hline
\end{tabular}

